\title{
INVESTIGATION OF TIME CHARACTERISTICS OF SEQUENCES OF MULTIFREQUENCY SIGNALS
}

\section{Levahin H. A., Piskunov S. M.}

\section{INTRODUCTION}

The result of the effect of electromagnetic radiation on the semiconductor base is the irreversible destruction of radioelements of functional devices: low-noise antenna amplifiers, crystal mixers, transistor intermediate frequency amplifiers and detectors. In this case, certain requirements must be met for the time and energy parameters of the impacting electromagnetic radiation ${ }^{1,2,3}$.

When evaluating the temporal parameters of electromagnetic radiation, it is necessary to take into account that in a number of cases, to protect the input circuits, special protection devices with a short response time can be used, blocking the receiving devices if there is not only a signal of their own transmitter at their input (with a combined receiving and transmitting antenna), but and high level of any other input signals. The response time of the best protection devices that have been implemented by industry is on the order of $10 \mathrm{~ns}{ }^{4,5,6}$. Therefore, the duration of the destructive signal $\tau$ p must correspond to the condition:

$$
\tau_{\mathrm{p}} \leq \tau_{\mathrm{K}}=10 \mathrm{~ns},
$$

where $\tau_{\mathrm{K}}$ - response time of protection devices when the specified maximum signal level in the input circuits is exceeded.

${ }^{1}$ Benford J., Swegle J. High-Power Microwave. Norxood. 1991. 412 p.

${ }^{2}$ Kravchenko V.I. Elektromagnitnoe oruzhie. Kharkov. 2008. 185 p.

${ }^{3}$ Ljob L. Basic processes of electric digits are in gases. 1950. 672 p.

4 Artsimovich L.A., Sagdeev R.Z. Plasma physics for physicists. Moscow. 1979. $320 \mathrm{p}$.

5 Myrova L.O., Chepizhenko A.Z. Ensuring stability of communications equipment to the ionizing and electromagnetic radiation. Moscow. 1988. 296 p.

${ }^{6}$ Magda I.I., Bludov S.P., Gadetski N.P. et al. Studies on electronic device degradation phenomena under interference of pulsed-power electromagnetic fields. 3-rd Int. Crimean Conf. "UNF Tech. and satellite reception". Sevastopol. 1993. Pp. 523-526. 
The purpose of the article is to evaluate the temporal characteristics of sequences of multifrequency spatio-temporal signals emitted by a cylindrical phased antenna array.

\section{Main material}

From a literature review, two variants of the effect of electromagnetic radiation on microprocessor equipment and semiconductor radioelements are known: in-band and out-of-band. In-band exposure requires accurate data, for example, about the operating frequency and bandwidth of the receiver, the clock frequency of a computer or special calculator, the resonant frequency of the structures of fasteners of electronic elements on boards, etc.

The energy loss of the acting electromagnetic energy when passing through the input circuits of the receiving path in this case depends on the ratio between the bandwidth of the receiving path $\Delta f_{n}$ and the bandwidth of the influencing signal $\Delta f_{p} \approx 1 / \tau_{p}$. In most cases, these losses do not exceed $-10 \ldots-15 \mathrm{~dB}^{7}$.

Out-of-band exposure does not require precise frequency range data. Impact can be made through the mounting holes at any frequencies outside their bandwidth.

The resulting losses in this case can reach the value $-30 \ldots-40 \mathrm{~dB}^{8,9,10,11}$.

As for the effects of influence on microprocessor technology, then, in addition to thermal breakdown of microcircuits, one can conditionally also include a failure of the clock frequency and, as a consequence, the so-called "freeze" of the program being executed. The latter is provided at lower energy costs.

The energy threshold for achieving the degradation effect of various electronic devices should be determined, taking into account, the

${ }^{7}$ Kravchenko V.I. Elektromagnitnoe oruzhie. Kharkov. 2008. 185 p.

${ }^{8}$ Iasechko M. Use of plasma technologies for the protection of radio electronic means from the influence of electromagnetic radiation. Kharkiv. 2017. Pp. 182-187. DOI: $10.20998 / 24134295$ 2017.53.25.

9 Kravchenko V., Bolotov E., Letunova N. Radio electronic facilities and powerful EMIS. Moscow. 1987. 256 p.

${ }^{10}$ Dobykyn V., Kupryianov A., Ponomarev V. Radio electronic fight. Power defeat of the radio electronic systems. Moscow. 2007. 487 p.

${ }^{11}$ Iasechko M. Plasma technologies for the protection of radio electronic means from exposure to high-power electromagnetic radiations with ultrashort pulse duration. Tallinn. 2017. Pp. 18-21. DOI: 0.21303/2585-6847.2017.00480. 
characteristic relaxation time of thermal processes, which for semiconductor devices and integrated circuits turns out to be quite large $\tau_{m} \geq 10 \ldots 100 \mathrm{~ns}^{12,13,14}$.

If the condition is met $\tau_{\mathrm{p}} \leq \tau_{\mathrm{K}}$ the condition $\tau_{\mathrm{p}} \leq \tau_{\mathrm{T}}$. In this case, the total effect can be estimated using the total time of the entire sequence of influencing signals minus the intervals between them, if the period of their repetition $\mathrm{T}_{\mathrm{p}}<\tau_{\mathrm{T}}$.

The smallest radiated power flux density can be achieved by creating spatio-temporal periodic short signals leading to self-excitation of the input stages or receiving devices in general.

With a sequence of multifrequency spatio-temporal signals to maintain stable self-excitation of the receiving devices, the duration of the acting pulses should be selected from the above condition (1). Suppose the condition $\tau \mathrm{p} \leq 5 \mathrm{~ns}$.

In turn, the following period Tp of such influencing impulses should be chosen in such a way that self-excitation oscillations decay by no more than $50 . . .70 \%$ :

$$
T_{p} \leq(0,7 \ldots 1,2) \tau_{n} \approx \frac{0,7 \ldots 1,2}{\pi \Delta f_{n}} \approx \frac{0,22 \ldots 0,38}{\Delta f_{n}},
$$

where $\Delta f_{n}$ and $\tau_{n}$ - bandwidth and settling time constant of natural oscillations of the receiving device.

Since the overwhelming majority of the bandwidth for real receivers is $\Delta \mathrm{f}_{\mathrm{n}} \leq 10 \mathrm{MHz}$ [4-12, 26], then, taking into account (2), we obtain $\mathrm{T}_{\mathrm{p}} \leq 220 \ldots 380 \mathrm{~ns}$ and accordingly, the value of the duty cycle of such periodic sequences of acting pulses $\tau_{\mathrm{p}} \leq 5 \mathrm{~ns}$ will be $Q=T_{p} / \tau_{p} \leq 50 \ldots 80$.

For further calculations, we choose the number of pulses $\mathrm{N}_{\mathrm{i}}=100$ at duty cycle $\mathrm{Q}<10$.

To determine the structure of the field emitted by a cylindrical phased array antenna with horn radiators, we use the following expression:

12 Dobykin V.D., Kupriyanov A.I., Ponomarev V.G., Shustov L.N. Electronic Warfare. Power failure of electronic systems. Moscow. 2007. 487 p.

13 Diakov A., Kuzhekyn I., Maksymov B., Temnykov A. Electromagnetic compatibility and lightning defence in an electroenergy. Moscow. 2009. 455 p.

${ }^{14}$ Iasechko M. Counteraction to the powerful electromagnetic radiation is for defence of radio electronic facilities. Kharkiv. 2017. Pp. 76-81. 


$$
\begin{aligned}
& \dot{\mathrm{E}}(P, t)=\sum_{m=1}^{M_{x}} \sum_{n=1}^{N_{y}} \frac{\dot{F}_{m n}\left(\beta_{\phi}, \alpha_{\phi}\right)}{R_{m n}} \sqrt{60 P_{m n} G_{\max m n}} \times \\
& \times \exp \left\{j\left[2 \pi f_{0 m n}\left(t-\frac{R_{m n}}{c}\right)+\phi_{0 m n}\right]\right\},
\end{aligned}
$$

where $\mathrm{m}$ and $\mathrm{n}$ - indices defining the number of the radiator; $\mathrm{M}_{\mathrm{x}}, \mathrm{N}_{\mathrm{y}}$ - the number of radiating elements along the guide and the generatrix of the cylinder, respectively; $\dot{F}_{m, n}\left(\beta_{\Phi}, \alpha_{\Phi}\right)$ - the value of the complex radiation pattern of the emitter in the direction to the focal point; $\beta_{\Phi}, \alpha_{\Phi}-$ angles defining the direction to the focus point; $\mathrm{R}_{\mathrm{mn}}$ - distance from emitter to focus point; $P_{m n}$ - power supplied to the mnth element of the phased array antenna; $\mathrm{G}_{\mathrm{mn}}$ - single emitter gain; $\mathrm{f}_{0 \mathrm{mn}}, \varphi_{0 \mathrm{mn}}-$ frequency and initial phase of the spectral component of multifrequency space-time signals supplied to the element of the phased array antenna; $\mathrm{t}$ - observation time.

The law of frequency variation along the aperture of a cylindrical phased antenna array will have the form:

$$
f_{0 m n}=\left\{\begin{array}{l}
f_{0}+v[m / v] \Delta F_{n \text { max }}, \\
f_{0}+v[n / v] \Delta F_{n \text { max }},
\end{array}\right.
$$

where $\mathrm{f}_{0 \mathrm{mn}}$ - frequency in $\mathrm{mn}$ emitter; $\mathrm{f}_{0}$ - middle frequency spectrum; $\Delta \mathrm{F}_{\mathrm{x}}, \Delta \mathrm{F}_{\mathrm{y}}-$ frequency sampling along the axes $\mathrm{O}_{\mathrm{x}}$ and $\mathrm{O}_{\mathrm{y}}$;

$$
\begin{gathered}
{[m / v] \Delta F_{n \max }=\left[\frac{f_{0} \frac{\rho_{m n}^{2}}{2 \gamma d_{x}^{2}-\rho_{m n}^{2}}}{v}\right] ;} \\
\gamma=1+\mathrm{f}_{0} / \Delta \mathrm{F}_{\mathrm{nmax}} ; \Delta \mathrm{Fnmax}=\max (\Delta \mathrm{Fx}, \Delta \mathrm{Fy}) ; \\
\rho_{m n}^{2}=x_{m n}^{2}+y_{m n}^{2} ;
\end{gathered}
$$

$v$ - duty cycle reduction factor.

Analysis of the calculations shows that in the case of using a multistage $\mathrm{V}$-shaped distribution law of carrier frequencies, with a decrease in the duty cycle of the formed sequence of signals, the pulse parameters do not change, only the structure of the side peaks changes. 
For example, figure 1 shows the normalized value of the electric field strength with the duty cycle $\mathrm{Q}=8$ for a range of $1 \mathrm{~km}$ and a signal spectrum width $2 \mathrm{GHz}$.

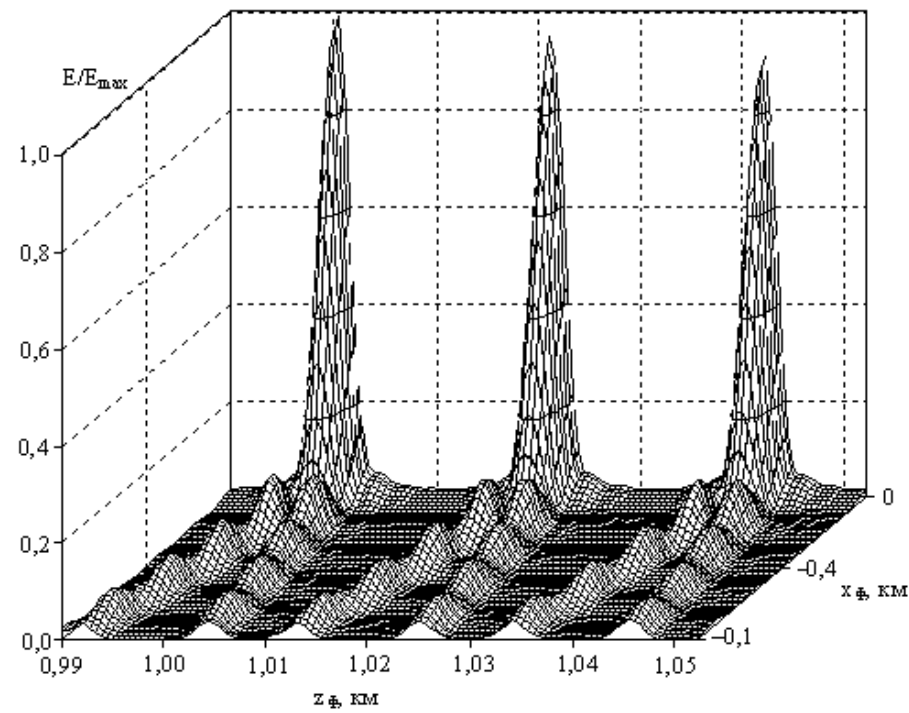

Fig. 1. The normalized value of the electric field strength $(Q=8)$

In figure 1 it follows that the spatial duration of the signal at the level of 0.5 is of the order of $1 \mathrm{~m}$, or $\tau_{\mathrm{i}}=3 \mathrm{~ns}$, the steepness of the leading edge is $1 \mathrm{~ns}$, the level of the first side lobe is of the order of $-10 \mathrm{~dB}$. Transverse size of the "spot" $\mathrm{x}_{\Phi}=7 \mathrm{~m}$.

In the vicinity of the lesion point $(\mathrm{R}=1 \mathrm{~km})$, the level of the first side lobe does not exceed $\mathrm{E}_{\mathrm{s}}<0,3 \mathrm{E}_{\max }$.

A decrease in the duty cycle leads to partial overlap of the far side lobes and a decrease in their level compared to the radiation field when using a single-stage V-shaped frequency distribution over the aperture.

Analysis of the calculation results also showed that the temporal structure of the multifrequency space-time signal emitted by a cylindrical phased antenna array in the azimuthal plane along the normal to the array does not depend on the azimuth of the target, since the space-frequency spectrum of the signal does not change. 
At the same time, when the elevation angle of the observed object changes, the conditions for the formation of a multifrequency spatiotemporal signal change, which leads to a change in its amplitude spectrum.

Figure 2 shows the amplitude-frequency spectrum of the radiated signal along the normal to the phased antenna array for $\mathrm{Q}=8$.

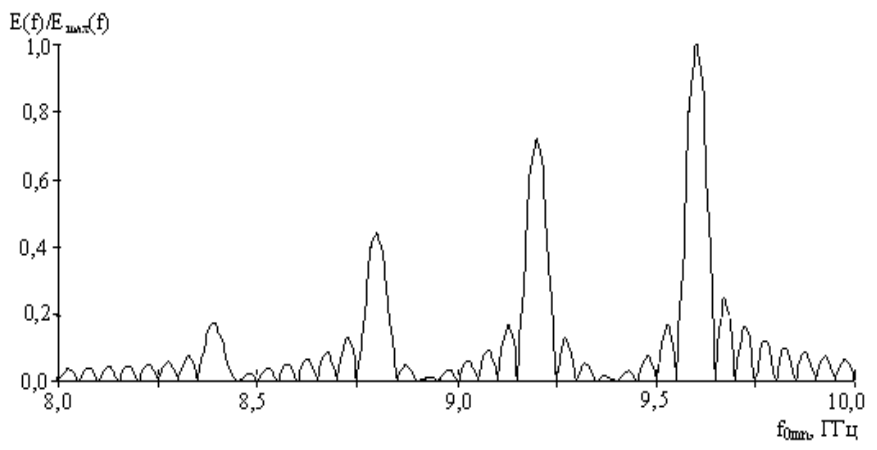

Fig. 2. Amplitude-frequency multifrequency space-time signal along the normal to the phased antenna array $(Q=8)$

Figure 3 shows the amplitude-frequency spectrum of the emitted signal when the focusing direction is shifted along the generatrix by an amount equal to the transverse linear size of the signal $d=x_{\Phi}$ when forming it along the normal to the lattice for $\mathrm{Q}=8$.

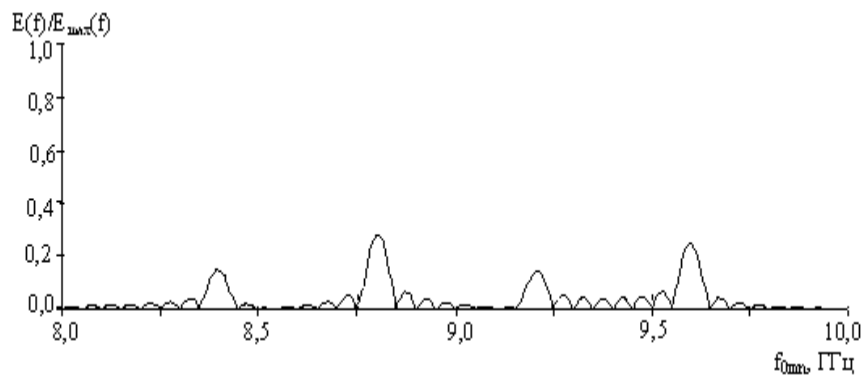

Fig. 3. Amplitude-frequency multifrequency space-time signal for $d=x \Phi(Q=8)$

Figure 4 shows the amplitude-frequency spectrum of the emitted signal when the focusing direction is shifted along the generatrix by an 
amount equal to two transverse linear dimensions of the space-time signal $\mathrm{d}=2 \mathrm{x}_{\Phi}$ when forming it along the normal to the lattice for $\mathrm{Q}=8$.

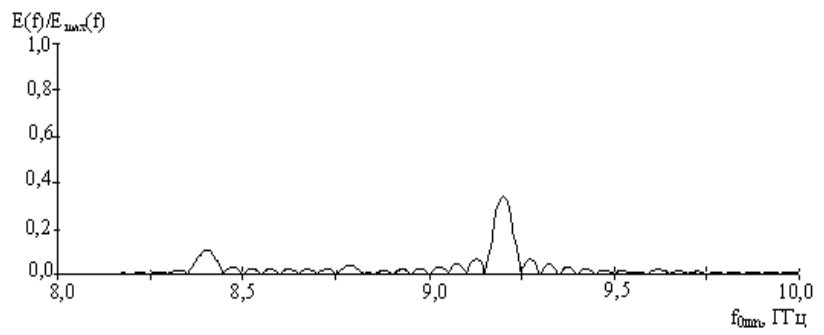

Fig. 4. Amplitude-frequency multifrequency space-time signal for $d=2 \times \Phi(Q=8)$

Similar results were obtained for the duty cycle $\mathrm{Q}=4$. Figure 5 shows the amplitude-frequency spectrum of the radiated signal along the normal to the phased array for $\mathrm{Q}=4$.

Figure 6 shows the amplitude-frequency spectrum of the radiated signal when the focusing direction is shifted along the generatrix by an amount equal to the transverse linear size of the multifrequency spacetime signal $\mathrm{d}=\mathrm{x}_{\Phi}$ when forming it along the normal to the lattice for $\mathrm{Q}=4$.

Figure 7 shows the amplitude-frequency spectrum of the emitted signal when the focusing direction is shifted along the generatrix by an amount equal to two transverse linear dimensions of the multifrequency space-time signal $d=2 x_{\Phi}$ when forming it along the normal to the lattice for $Q=4{ }^{15,16}$.

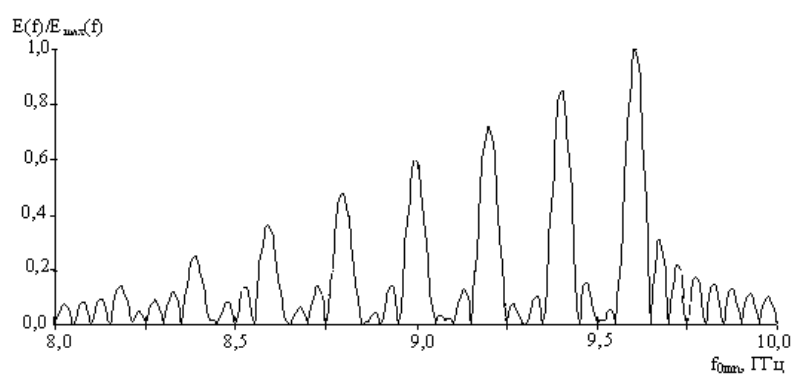

${ }^{15}$ Iasechko M. Counteraction to the powerful electromagnetic radiation is for defence of radio electronic facilities. Kharkiv. 2017. Pp. 76-81.

${ }^{16}$ Starostenko V.V., Grigoriev V.V., Taran E.P. The impact of electromagnetic fields on the stability of the IC. Mat. of 6-th Int. Crimean Microwave Conf. (Sevastopol, Sept. 16-19. 1996). Sevastopol. 1996. Pp. 188-191. 
Fig. 5. Amplitude-frequency multifrequency space-time signal of the signal along the normal to the phased array antenna $(Q=4)$

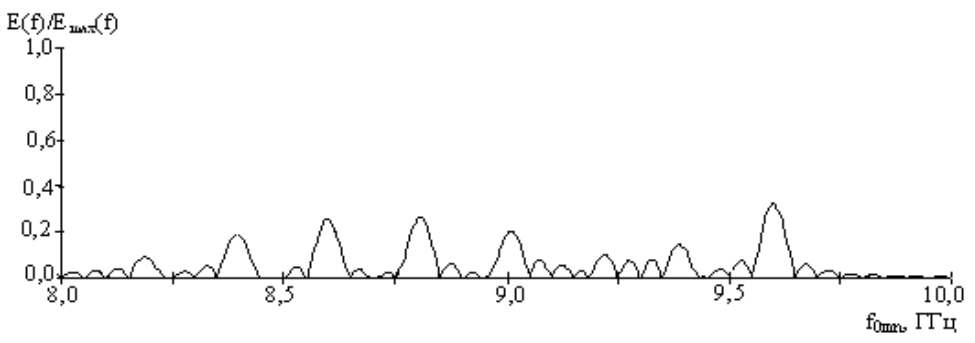

Fig. 6. Amplitude-frequency multifrequency space-time signal for $d=x \Phi(Q=4)$

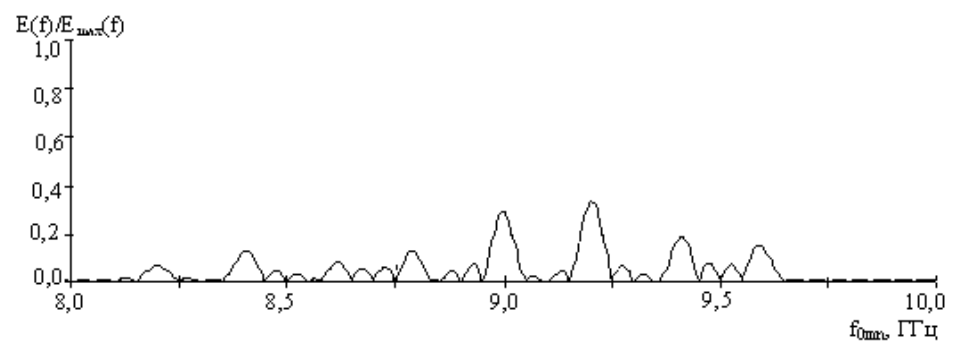

Fig. 7. Amplitude-frequency multifrequency space-time signal for $\mathbf{d}=\mathbf{2} \mathbf{x}_{\Phi}(Q=\mathbf{4})$

From the analysis of figure $2-7$ it follows that when the focusing point moves away from the direction of the normal to the axis of the antenna array, the multifrequency spatio-temporal signal is "blurred", the electric field strength decreases significantly (up to 70\%), the structure of the amplitude-frequency spectra becomes irregular and tends to the noise-like $e^{17,18}$.

In order to make it possible to scan in directions other than the direction of the normal to the axis of the phased antenna array, it is necessary to provide an additional linear phase distribution, which allows scanning the radiation pattern.

17 Baliuk N., Kechyev L., Stepanov P. Powerful electromagnetic impulse: affecting electronic facilities and methods of defence. Moscow. 2007. 478 p.

${ }^{18}$ Bohush V., Borbotko T., Husynskyi A. Electromagnetic radiations. Methods and facilities of defence. Minsk. 2003. 406 p. 
To carry out scanning at a certain distance, it is advisable to provide for the possibility of creating a sequence of multifrequency spatiotemporal signals in directions other than the direction of the normal to the axis of the cylindrical phased antenna array. The coordinates of an object in the general case can be calculated if, at a given time, the coordinates of the trajectory of the tracked object are extrapolated on the basis of radar information obtained in previous time readings.

Based on the known rectangular coordinates of the focusing point at a given moment in time, their new values in a spherical coordinate system associated with a phased array antenna can be calculated as ${ }^{19}$ :

$$
\left\{\begin{array}{l}
\mathrm{R}(\mathrm{t})=\sqrt{\mathrm{x}_{\Phi}(\mathrm{t})^{2}+\mathrm{y}_{\Phi}(\mathrm{t})^{2}+\mathrm{z}_{\Phi}(\mathrm{t})^{2},} \\
\varepsilon(\mathrm{t})=\arccos \left[\mathrm{z}_{\Phi}(\mathrm{t}) / \mathrm{R}_{\mathrm{n}}(\mathrm{t})\right], \\
\beta(\mathrm{t})=\operatorname{arctg}\left[\mathrm{z}_{\Phi}(\mathrm{t}) / \mathrm{y}_{\Phi}(\mathrm{t})\right],
\end{array}\right.
$$

where $\mathrm{R}, \beta, \varepsilon-$ spherical coordinates; $\mathrm{x}_{\Phi}, \mathrm{y}_{\Phi}, \mathrm{z}_{\Phi}$ - cartesian coordinates.

Knowledge of the angular coordinate by the elevation angle allows you to specify an additional phase distribution in the form of a linear term to expression (2), which ensures the deviation of the radiation pattern from the direction of the normal to the phased antenna array in elevation $^{20,21}$

The addition in the plane of the generatrix (azimuthal direction) is impractical to set due to the axisymmetric design of the cylindrical phased array antenna ${ }^{22}$.

It is known ${ }^{23}$ that for scanning it is necessary to set an additional linear phase distribution along the aperture of the phased array antenna.

19 Ricketts L.U., Bridges J.J. Mayletta electromagnetic pulse and methods of protection. Moscow. 1979. 328 p.

20 Kravchenko V. Lightning guard of radio electronic facilities. Moscow. 1991. 264 p.

21 Dobykyn V., Kupryianov A., Ponomarev V. Radio electronic fight. Power defeat of the radio electronic systems. Moscow. 2007. 487 p.

${ }^{22}$ Magda I.I., Bludov S.P., Gadetski N.P. et al. Studies on electronic device degradation phenomena under interference of pulsed-power electromagnetic fields. 3-rd Int. Crimean Conf. "UNF Tech. and satellite reception". Sevastopol. 1993. Pp. 523-526.

${ }^{23}$ Alybin V.G. Problems of creation of protective devices for microwave radar and communication. 12th Int. Crimean Conference "Microware Telecommunication Technology” (Sevastopol, 9-13 September. 2002). Sevastopol. 2002. Pp. 15-21. 
In the case under consideration, the addition in the elevation plane $\varphi 0 \varepsilon$ has the form:

$$
\phi_{0 \varepsilon}\left(x_{n}\right)=-a(t) x_{n},
$$

where $\mathrm{a}(\mathrm{t})=\frac{\pi \mathrm{L}}{\lambda} \sin \varepsilon(\mathrm{t}) \cos \beta(\mathrm{t})$ - phase slope in the elevation plane.

In the case of focusing on a moving point, the coefficients a (t) will depend on time in accordance with the given law of motion of the object, determined by $(3)^{24}$.

In this case, the expression for the electric field strength (2) for focusing to the point of the trajectory will have the form:

$$
\begin{aligned}
& \dot{E}(P, t)=\sum_{m=1}^{M_{x}} \sum_{n=1}^{N_{y}} \frac{\dot{F}_{m n}\left(\beta_{\Phi}, \alpha_{\Phi}\right)}{R_{m n}} \sqrt{60 P_{m n} G_{m a x m n}} \times \\
& x \exp \left\{j\left[2 \pi f_{0 m n}\left(t-\frac{R_{m n}}{c}\right)+f_{0 m n}+a(t) x_{n}\right]\right\},
\end{aligned}
$$

Expression (4) describes the electric field strength in a direction other than the normal to the cylindrical axis (4). It is obvious that the amplitude-frequency spectrum of the multifrequency space-time signal in this case does not change.

\section{Estimation of the error in the location of the phase centers of the emitters in the cylindrical phased antenna array}

The quality of the formation of a multifrequency spatio-temporal signal depends on the degree of provision of the specified coordinates of the phase centers of the radiation sources. However, when creating specific samples, errors in ensuring the selected coordinates are possible and the laws of

${ }^{24}$ Starostenko V.V., Grigoriev V.V., Taran E.P. The impact of electromagnetic fields on the stability of the IC. Mat. of 6-th Int. Crimean Microwave Conf. (Sevastopol, Sept. 16-19. 1996). Sevastopol. 1996. Pp. 188-191.

Artsimovich L.A., Sagdeev R.Z. Plasma physics for physicists. Moscow. 1979. $320 \mathrm{p}$.

Myrova L.O., Chepizhenko A.Z. Ensuring stability of communications equipment to the ionizing and electromagnetic radiation. Moscow. 1988. 296 p.

Magda I.I., Bludov S.P., Gadetski N.P. et al. Studies on electronic device degradation phenomena under interference of pulsed-power electromagnetic fields. 3-rd Int. Crimean Conf. "UNF Tech. and satellite reception". Sevastopol. 1993. Pp. 523-526. 
change in instantaneous phases will not correspond to the given requirement of signal formation at a given point in space. $\mathrm{P}_{\phi}\left(\mathrm{x}_{\phi}, \mathrm{y}_{\phi}, \mathrm{z}_{\phi}\right)$.

To substantiate the requirements for the accuracy of the location of the phase centers of emitters in a cylindrical phased antenna array with pyramidal horns, it is advisable to calculate the radiation field using single-stage and multi-stage $\mathrm{V}$-shaped frequency distribution laws in the presence of the indicated errors.

The influence of errors in the location of the phase centers of individual radiation sources with an equiprobable law of their distribution on the mathematical expectation of the normalized electric field strength of a cylindrical phased array antenna can be obtained as:

$$
\begin{aligned}
\left\langle E\left(P_{\phi}, t\right)\right\rangle=\left\langle\frac{1}{E_{\max }} \sum_{m=-\frac{M_{x}-1}{2}}^{\frac{M_{x}-1}{2}} \sum_{n=-\frac{N_{y}-1}{2}}^{\frac{N_{y}-1}{2}} \frac{A_{m n} F_{m n}\left(n_{\phi}, \Theta_{\phi}\right)}{R_{m n}} \sqrt{60 P_{m n} G_{\max m n}} \times .\right. \\
\left.\quad \quad \exp \left(-j\left[2 \pi f_{0 m n}\left[t-\frac{R_{m n}^{\text {ow }}}{c}\right]+n_{0 m n}\right]\right)\right\rangle
\end{aligned}
$$

where $\mathrm{E}_{\max }$ - the maximum value of the electric field strength emitted by the cylindrical phased antenna array.

The distance to the observation point from each radiating element, taking into account the errors in the location of the phase centers, is:

$$
\mathrm{R}_{\mathrm{mn}}^{\text {ow }}=\sqrt{\left(\mathrm{x}_{\phi}-\mathrm{X}_{\mathrm{mn}}^{\text {ow }}\right)^{2}+\left(\mathrm{y}_{\phi}-\mathrm{y}_{\mathrm{mn}}^{\text {oш }}\right)^{2}+\left(\mathrm{z}_{\phi}-\mathrm{z}_{\mathrm{mn}}^{\text {oш }}\right)^{2}},
$$

where $x_{m n}^{\text {ow }}=x_{m n}+\frac{\Delta \rho}{\sqrt{2}} \Psi_{1}, \quad y_{m n}^{\text {ow }}=y_{m n}+\frac{\Delta \rho}{\sqrt{2}} \Psi_{2}, \quad z_{m n}^{\text {ow }}=\Delta h \Psi_{3}-$ values of coordinates of phase centers of radiation sources of a cylindrical phased antenna array, taking into account errors; $\Delta \rho$ and $\Delta \mathrm{h}$ - maximum values of errors in the location of phase centers of radiation sources; $\Psi_{1}, \Psi_{2}, \Psi_{3}$ - random numbers uniformly distributed in the interval [-1,1].

The calculation of the electric field strength, taking into account errors, will be carried out for the case: the number of "working" elements $\mathrm{N}=\mathrm{M}_{\mathrm{X}} \times \mathrm{N}_{\mathrm{Y}}=88 \times 20=1760$; maximum aperture size $\mathrm{L}=1 \mathrm{~m}$; cylinder radius $1.25 \mathrm{~m}$; lattice spacing along the guide $\mathrm{d}_{\mathrm{x}}=1,0 \lambda$, along the generatrix $d_{z}=0,8 \lambda$; uniform amplitude distribution $A(x, y)=1$.

Taking into account the selected wavelength range, the frequency discreteness between adjacent radiators is chosen 
$\Delta \mathrm{F}_{\mathrm{y}}=2 \mathrm{GHz} / 10=200 \mathrm{MHz}, \Delta \mathrm{F}_{\mathrm{x}}=2 \mathrm{Ghz} / 44=45 \mathrm{MHz}$ and, accordingly, the maximum carrier frequency spacing over the phased array aperture is $\mathrm{F}_{\mathrm{x} \max }=\mathrm{F}_{\mathrm{ymax}}=2 \mathrm{GHz}$. This makes it possible to form a sequence of a multifrequency spatio-temporal signal with a duration $\tau_{\mathrm{s}}=3 \mathrm{~ns}$ with a repetition period $T_{p}=250$ ns.

Figure 1 shows the dependences of the mathematical expectation of the normalized value of the electric field strength cylindrical phased array antenna from errors $\Delta \rho$ and $\Delta \mathrm{h}$, calculated in accordance with (1) using a single-stage $\mathrm{V}$-shaped frequency distribution over the aperture for $\mathrm{R}=5 \mathrm{~km}$.

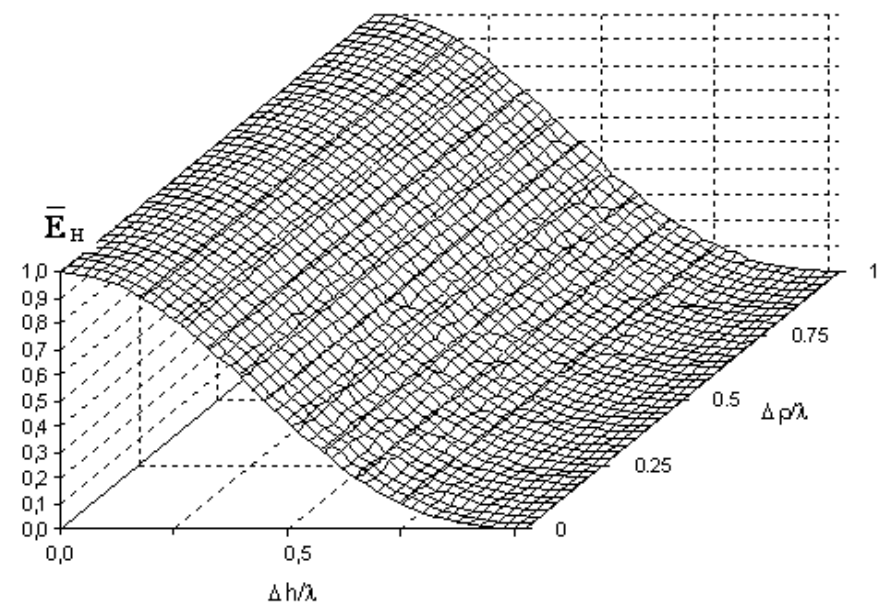

Fig. 8. Dependence of the mathematical expectation of the normalized electric field strength on errors $\Delta \rho$ and $\Delta h$

Figure 8 shows similar dependencies $\overline{\mathrm{E}}_{\mathrm{H}}$ cylindrical phased antenna array along the normal to the generatrix depending on the distance without taking into account the errors in the location of the radiators $(\Delta \rho=0 ; \Delta \mathrm{h}=0)$, and also taking into account the maximum values of errors both in the plane of the generator at $\Delta \rho=\lambda$, and in the plane of the guide at $\Delta \mathrm{h}=\lambda / 6$ for $\mathrm{R}=5 \mathrm{~km}$. 


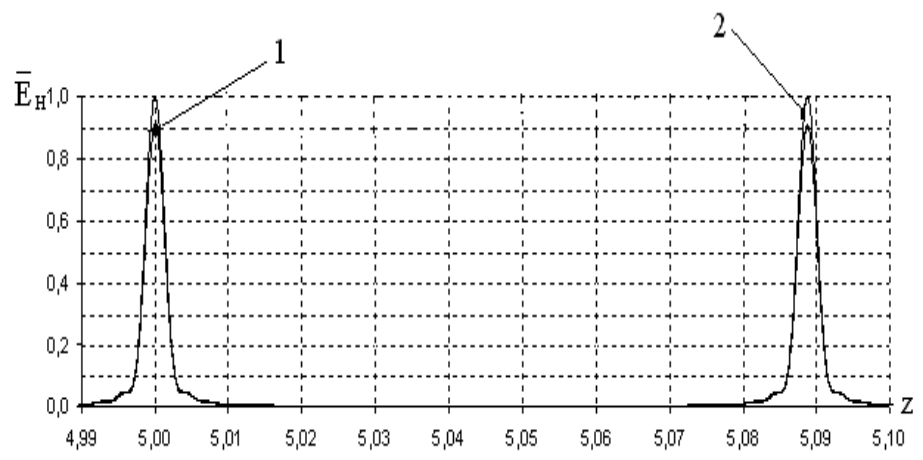

Fig. 9. Impact of errors $\Delta \rho$ and $\Delta \mathrm{h}$ on the distribution of the electric field of the phased array antenna by range $(1-\Delta \rho=0 ; \Delta h=\lambda / 6)$

As can be seen from Figures 8 and 9, the effect of errors in the location of the emitters in the plane of the generatrix in the far zone becomes insignificant. The influence of errors in the location of the phase centers of the emitters in the plane of the guide does not depend on the distance to the focusing point. The calculation results also showed that the influence of errors in the location of the emitters in the plane of the generatrix on the level of the electric field of the multifrequency spatio-temporal signal affects only in the Fresnel zone. Range of valid values $\Delta \mathrm{h}$, in which decreasing the value $\mathrm{E}_{\mathrm{H}}$ does not exceed $10 \%$, is determined from the condition:

$$
\Delta \mathrm{h} \leq \lambda / 6 .
$$

Figure 10 shows the dependencies $\overline{\mathrm{E}}_{\mathrm{H}}=\left\langle\mathrm{E}(\mathrm{x}, \mathrm{y}, \mathrm{z}, \mathrm{t}) / \mathrm{E}_{\max }\right\rangle$ in the direction of the normal to the aperture of the cylindrical phased antenna array without taking into account errors in the location of the radiators ( $\Delta \rho=0 ; \Delta \mathrm{h}=0$ ), and also taking into account the maximum values of errors in the plane of the generator, equal to $\Delta \rho=\lambda$, and in the plane of the guide equal to, when using a multistage $\mathrm{V}$-shaped law of frequency distribution over the aperture with the parameter $v=4(Q=12)$ for $z=5 \mathrm{~km}$. 


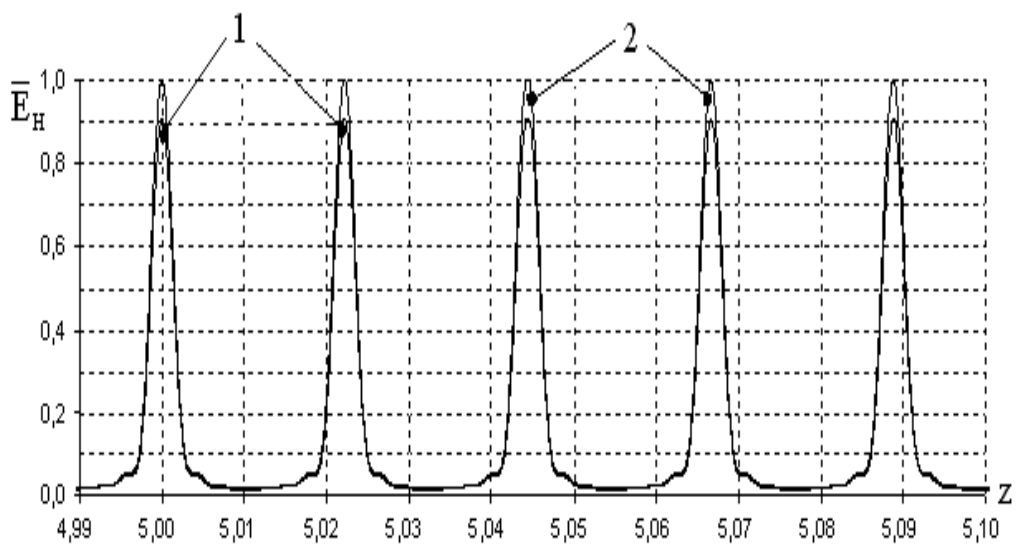

Fig. 10. Impact of errors $\Delta \rho$ and $\Delta \mathrm{h}$ on the distribution of the electric field strength of a cylindrical phased antenna array along the range at $v=4(Q=12)$

As can be seen from Figure 10, the influence of errors in the location of the phase centers of the emitters is of the same nature as in the previous case. Range of valid values, in which decreasing the value $\overline{\mathrm{E}}_{\mathrm{H}}$ is no more $10 \%$.

The performed mathematical modeling shows that the errors in the location of the phase centers of individual radiation sources of a cylindrical phased antenna array, equal to $\Delta \rho \leq \lambda$ and $\Delta \mathrm{h} \leq \lambda / 6$, have practically no effect on the duration and repetition period of a multifrequency space-time signal.

\section{CONCLUSIONS}

The calculation of the amplitude - frequency spectra of multifrequency space - time signals at different elevation angles has been carried out. When the lesion point is removed from the direction of the normal to the axis of the phased array, the multifrequency spatiotemporal signal is "blurred", the electric field strength significantly decreases (up to 70\%), the structure of the amplitude-frequency spectra becomes irregular and tends to noise-like.

A method is proposed for calculating an additional linear phase distribution for scanning with a cylindrical radiation pattern (4) in elevation. 


\section{SUMMARY}

The influence of these instabilities on the peak power level, duration and repetition period of a multifrequency spatio-temporal signal is considered, and we estimate the maximum values of the errors of the parameters of the laws of spatial-phase-frequency control of signals.

The requirements for the accuracy of the location of the phase centers of the emitters in a cylindrical phased antenna array with pyramidal horns have been substantiated; it is advisable to calculate the radiation field using single-stage and multi-stage $\mathrm{V}$-shaped frequency distribution laws in the presence of the indicated errors.

The analysis of the location of the phase centers of individual radiation sources of a cylindrical phased antenna array has been carried out; they practically do not affect the duration and repetition period of a multifrequency spatio-temporal signal.

\section{REFERENCES}

1. Benford J., Swegle J. High-Power Microwave. Norxood. 1991. 412 p.

2. Kravchenko V.I. Elektromagnitnoe oruzhie. Kharkov. 2008. 185 p.

3. Dobykin V.D., Kupriyanov A.I., Ponomarev V.G., Shustov L.N. Electronic Warfare. Power failure of electronic systems. Moscow. 2007. $487 \mathrm{p}$.

4. Starostenko V.V., Grigoriev V.V., Taran E.P. The impact of electromagnetic fields on the stability of the IC. Mat. of 6-th Int. Crimean Microwave Conf. (Sevastopol, Sept. 16-19. 1996). Sevastopol. 1996. Pp. 188-191.

5. Artsimovich L.A., Sagdeev R.Z. Plasma physics for physicists. Moscow. 1979. 320 p.

6. Myrova L.O., Chepizhenko A.Z. Ensuring stability of communications equipment to the ionizing and electromagnetic radiation. Moscow. 1988. 296 p.

7. Magda I.I., Bludov S.P., Gadetski N.P. et al. Studies on electronic device degradation phenomena under interference of pulsed-power electromagnetic fields. 3-rd Int. Crimean Conf. "UNF Tech. and satellite reception”. Sevastopol. 1993. Pp. 523-526.

8. Vorobiov O., Savchenko V., Sotnikov A., Tarshin V., Kurtseitov T. Development of radioisotopic-plasmatechnology for the protection of radio electronic means from powerful electromagnetic radiation. Eastern-European Journal of Enterprise Technologies. 2017. Vol. 1, No. 5(85). Pp. 16-22. DOI: 10.15587/1729-4061.2017.91642. 
9. Krutov A., Mitmen V., Rebrov A. Protector of the small power level. Materials proc. 12-th International Crimean Conference "Microwave equipment" Sevastopol. 2002. Pp. 93-94.

10. Ricketts L.U., Bridges J. J. Mayletta electromagnetic pulse and methods of protection. Moscow. 1979. 328 p.

11. Alybin V.G. Problems of creation of protective devices for microwave radar and communication. 12-th Int. Crimean Conference "Microware Telecommunication Technology" (Sevastopol, 9-13 September. 2002). Sevastopol. 2002. Pp. 15-21.

12. Ropy A.N., Starik A.M., Shutov K.K. Microwave protective device. Moscow. 1993. 128 p.

13. Krizny A.V., Vorobyov O.M., Sotnikov O.M. Designing the structure of the material of the protective screens of radio-electronic means of arms and military equipment from the effects of powerful electromagnetic radiation pulse duration. Trudy Universitetu. 2013. No. 6 (120). Pp. 187-191.

14. Baliuk N., Kechyev L., Stepanov P. Powerful electromagnetic impulse: affecting electronic facilities and methods of defence. Moscow. 2007. $478 \mathrm{p}$.

15. Bohush V., Borbotko T., Husynskyi A. Electromagnetic radiations. Methods and facilities of defence. Minsk. 2003. 406 p.

16. Mykhailov V. Providing of firmness of side digital calculable machines to influence of supershort electromagnetic impulses. Moscow. 2009. 24 p.

17. Diakov A., Kuzhekyn I., Maksymov B., Temnykov A. Electromagnetic compatibility and lightning defence in an electroenergy. Moscow. 2009. 455 p.

18. Iasechko M. Use of plasma technologies for the protection of radio electronic means from the influence of electromagnetic radiation. Kharkiv. 2017. Pp. 182-187. DOI: 10.20998/24134295 2017.53.25.

19. Kravchenko V., Bolotov E., Letunova N. Radio electronic facilities and powerful EMIS. Moscow. 1987. $256 \mathrm{p}$.

20. Kravchenko V. Lightning guard of radio electronic facilities. Moscow. 1991. 264 p.

21. Dobykyn V., Kupryianov A., Ponomarev V. Radio electronic fight. Power defeat of the radio electronic systems. Moscow. 2007. 487 p.

22. Iasechko M. Plasma technologies for the protection of radio electronic means from exposure to high-power electromagnetic radiations with ultrashort pulse duration. Tallinn. 2017. Pp. 18-21. DOI: 0.21303/2585-6847.2017.00480. 
23. Iasechko M. Counteraction to the powerful electromagnetic radiation is for defence of radio electronic facilities. Kharkiv. 2017. Pp. 76-81.

24. Ljob L. Basic processes of electric digits are in gases. 1950. $672 \mathrm{p}$.

\section{Information about authors:}

Levahin H. A.,

$\mathrm{PhD}$ of Engineering Sciences, Head of the Faculty of Air Defense of the Land Forces Ivan Kozhedub Kharkiv National Air Force University 77/79, Sumska str., Kharkiv, 61000, Ukraine

Piskunov S. M., $\mathrm{PhD}$ of Engineering Sciences, Head of the Department of Air Defense Armaments of the Land Forces Ivan Kozhedub Kharkiv National Air Force University 77/79, Sumska str., Kharkiv, 61000, Ukraine 